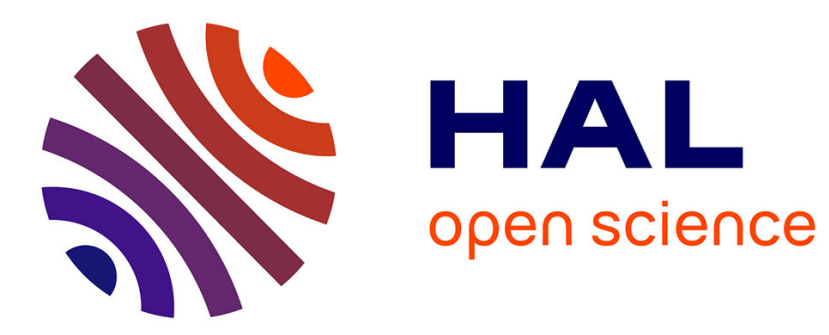

\title{
Magnetic ordering in Ce3Al11
}

G. Chouteau, J. Flouquet, J.P. Keradec, J. Palleau, J. Peyrard, R. Tournier

\section{To cite this version:}

G. Chouteau, J. Flouquet, J.P. Keradec, J. Palleau, J. Peyrard, et al.. Magnetic ordering in Ce3Al11. Journal de Physique Lettres, 1978, 39 (23), pp.461-463. 10.1051/jphyslet:019780039023046100 . jpa00231545

\section{HAL Id: jpa-00231545 https://hal.science/jpa-00231545}

Submitted on 1 Jan 1978

HAL is a multi-disciplinary open access archive for the deposit and dissemination of scientific research documents, whether they are published or not. The documents may come from teaching and research institutions in France or abroad, or from public or private research centers.
L'archive ouverte pluridisciplinaire HAL, est destinée au dépôt et à la diffusion de documents scientifiques de niveau recherche, publiés ou non, émanant des établissements d'enseignement et de recherche français ou étrangers, des laboratoires publics ou privés. 


\title{
MAGNETIC ORDERING IN $\mathrm{Ce}_{3} \mathrm{Al}_{11}\left(^{*}\right)$
}

\author{
G. CHOUTEAU \\ Service National des Champs Intenses, C.N.R.S., B.P. 166 X, 38042 Grenoble Cedex, France \\ J. FlOUQUeT, J. P. KERADEC, J. PAlleAU, J. PEYRARD and R. TOURNIER \\ Centre de Recherches sur les Très Basses Températures, C.N.R.S., B.P. 166 X, \\ 38042 Grenoble Cedex, France
}

(Reçu le 23 août 1978, accepté le 17 octobre 1978)

\begin{abstract}
Résumé. - Les propriétés magnétiques de $\mathrm{Ce}_{3} \mathrm{Al}_{11}$ ont été étudiées sous pression à basses températures. Il semble que certains des effets observés dans $\mathrm{CeAl}_{3}$ soient dus à la présence en faible quantité d'une phase parasite $\mathrm{Ce}_{3} \mathrm{Al}_{11}$.
\end{abstract}

\begin{abstract}
The magnetic properties of $\mathrm{Ce}_{3} \mathrm{Al}_{11}$ have been studied at low temperatures under pressure. We show that some of the striking properties of $\mathrm{CeAl}_{3}$ may be due to the presence of small amounts of $\mathrm{Ce}_{3} \mathrm{Al}_{11}$.
\end{abstract}

Among the Ce compounds, those with $\mathrm{Al}$ exhibit striking properties : Kondo behaviour has been observed in $\mathrm{CeAl}_{2}, \mathrm{CeAl}_{3}$ and probably in $\mathrm{Ce}_{3} \mathrm{Al}_{11}$ at high temperatures $[1,2,3,4]$.

However the low temperature properties of these three compounds are very different. $\mathrm{CeAl}_{2}$ is ordered at $T=0$ but for $\mathrm{CeAl}_{3}$ the situation is not clear. Its low temperature properties seem to be characteristic of a non-magnetic ground state : high linear temperature term of the specific heat, $T^{2}$ dependence of the resistivity [5]. $\mathrm{CeAl}_{3}$ could be a Kondo lattice at $T=0$. However some other properties namely the presence of two well marked peaks in the specific heat at 2.5 and $6 \mathrm{~K} \mathrm{[2]} \mathrm{are} \mathrm{unexplained.} \mathrm{We} \mathrm{have} \mathrm{recently} \mathrm{shown}$ that a weak remanent magnetization appears just at $6 \mathrm{~K}$ and increases down to $2.5 \mathrm{~K}$ where it decreases abruptly to a very low value. Moreover under a $6 \mathrm{kbar}$ pressure only the anomaly at $6 \mathrm{~K}$ remains in the specific heat; this phenomena is correlated to the persistence of the remanent magnetization below $2.5 \mathrm{~K}$. If these properties are intrinsic to $\mathrm{CeAl}_{3}$, this compound could be the first example of a compound magnetically ordered between two temperatures and finally non-magnetic at low temperature [6]. However the purity of $\mathrm{CeAl}_{3}$ is a crucial problem as this

$\left(^{*}\right)$ This paper has been presented at the LT 15 Conference as a post-deadline paper. compound does not exist in the liquid phase. We have shown [2] that the peak observed previously at $4.2 \mathrm{~K}$ in the specific heat was due to the presence of a parasitic phase of $\mathrm{CeAl}_{2}$ and could be eliminated by an appropriate annealing.

In this same spirit, we have investigated the magnetic properties of $\mathrm{Ce}_{3} \mathrm{Al}_{11}$ in order to check whether or not the observed properties of $\mathrm{CeAl}_{3}$, namely the two peaks at $6 \mathrm{~K}$ and $2.5 \mathrm{~K}$ in the specific heat are due to the presence of a parasitic phase.

The polycristalline sample was prepared in an a.c. furnace by a semi-levitation method.

The magnetization was measured at the S.N.C.I. Laboratory in Grenoble 1) between 1.4 and $4.2 \mathrm{~K}$ in a maximum field of $15 \mathrm{~T}$ by a classical extraction model, 2) between $4 \mathrm{~K}$ and $300 \mathrm{~K}$ in a vibrating pick-up coil experiment. a.c. susceptibility measurements have been also performed below $15 \mathrm{~K}$ down $1.2 \mathrm{~K}$. The two series of measurements were performed at $P=0$ and $P \simeq 6$ bars in a $\mathrm{CuBe}$ sample holder.

1. Experimental results. - 1) Above $9 \mathrm{~K}$ the susceptibility follows a Curie-Weiss law at least up to $100 \mathrm{~K}$ with a paramagnetic Curie temperature $\theta \simeq-25 \mathrm{~K}$ and an effective moment $\mu_{\text {eff }}$ determined without any correction, equal to $2.2 \mu_{\mathrm{B}}$ in good agreement with previous results [3]. Both $\theta$ and $\mu_{\text {eff }}$ are pressure independent. 
2) Below $6 \mathrm{~K}$ a more complicated behaviour is observed. The compound exhibits a remanent magnetization which increases up to a maximum value of $0.1 \mu_{\mathrm{B}} /$ at. Ce at $4.2 \mathrm{~K}$, decreases abruptly at $2.5 \mathrm{~K}$ and then remains constant at lower temperatures (Fig. 1), with a very low value of $\simeq 0.01 \mu_{\mathrm{B}} /$ at .Ce. Between 2.5 and $6 \mathrm{~K}$ (Fig. 2) the magnetization curves show a ferromagnetic-type behaviour, however with an unusual

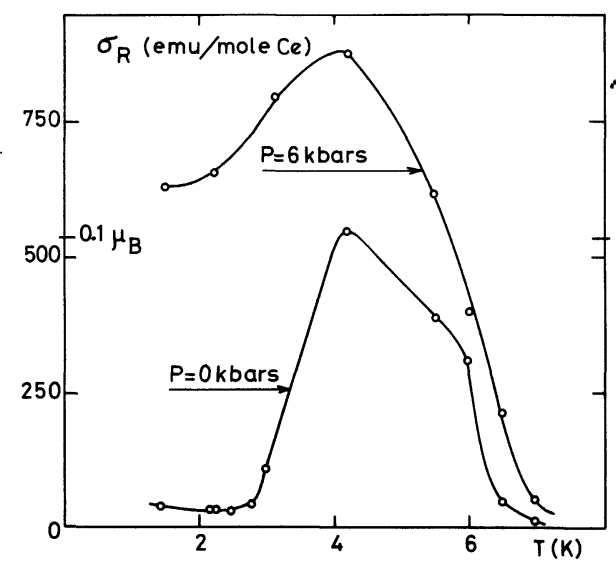

Fig. 1. - Remanent magnetization of $\mathrm{Ce}_{3} \mathrm{Al}_{11}$ at $P=0$ and $P=6 \mathrm{kbars}$ between 1.4 and $4.2 \mathrm{~K}$.

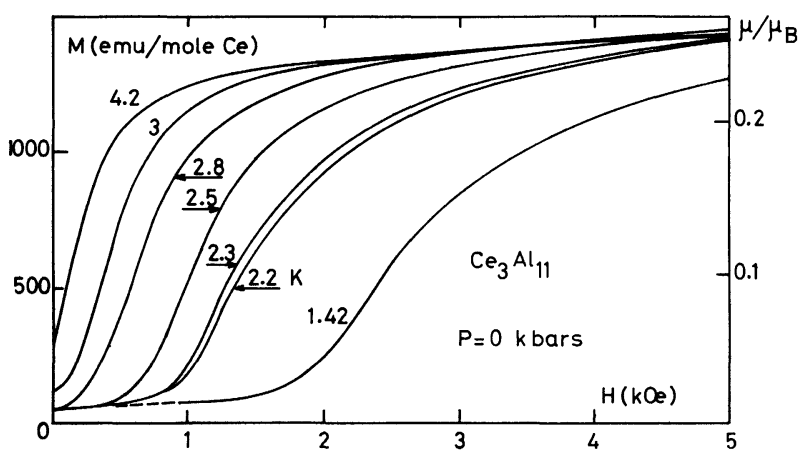

FIG. 2. - Magnetization curves of $\mathrm{Ce}_{3} \mathrm{Al}_{11}$ between 0 and $5 \mathrm{kOe}$ at $P=0$ in the range $1.4-4.2 \mathrm{~K}$.

shape which may be due to the strong anisotropy of the orthorhombic lattice [7]. The magnetization, which is twice its remanent value at $1 \mathrm{kOe}$, reaches only $0.7 \mu_{\mathrm{B}} /$ at. Ce in $150 \mathrm{kOe}$ at $1.4 \mathrm{~K}$ (Fig. 3). A simple picture is that in a first step the magnetic moment is aligned, along each preferential axis of a microcrystal and that in a second step each component of the microcrystal is slowly oriented along the $H$ magnetic field since the preferential axes are randomly distributed with respect to $H$.

In the temperature range corresponding to the low remanent magnetization $(T<2.5 \mathrm{~K})$ a transition occurs in the magnetization curves. It is similar to a metamagnetic transition but is not first order. The slope $\mathrm{d} M / \mathrm{d} H$ is always much lower than the reciprocal demagnetization factor. Above the critical field the magnetization reaches the same value as in the ferromagnetic regime.

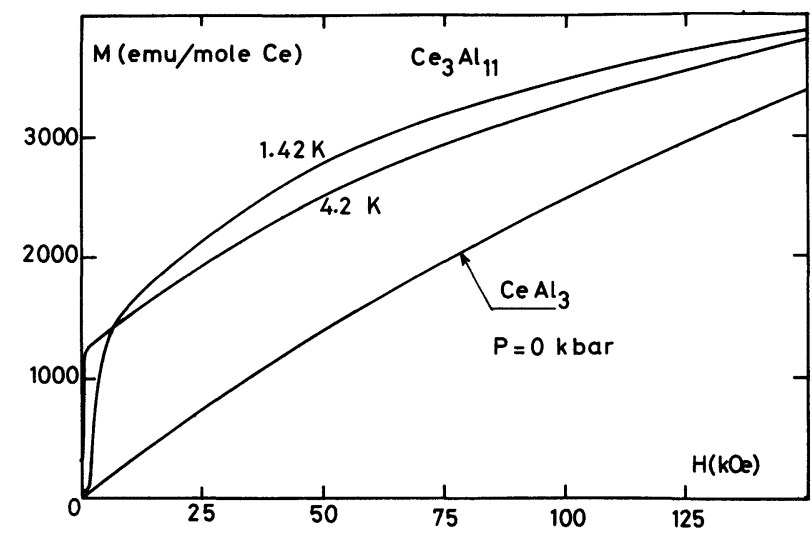

FIG. 3. - Magnetization of $\mathrm{Ce}_{3} \mathrm{Al}_{11}$ in $150 \mathrm{kOe}$ at 4.2 and $1.43 \mathrm{~K}$ (upper curves). The magnetization curve of a sample of $\mathrm{CeAl}_{3}$ at $4.2 \mathrm{~K}$ is given for comparison (lower curve).

3) Under a pressure of 6 kbars the abnormal behaviour no longer exists below $2.5 \mathrm{~K}$. As shown on the figure 1 the remanent magnetization which continues to appear abruptly at $6 \mathrm{~K}$ has only a slight decrease below $2.5 \mathrm{~K}$.

4) Recently, by measuring different samples of $\mathrm{CeAl}_{3}$, we have concluded that the remanent properties, previously detected between 2.5 and $6 \mathrm{~K}[2,6]$ are due to the presence of a parasitic phase of $\mathrm{Ce}_{3} \mathrm{Al}_{11}$. For different samples, the $\mathrm{Ce}_{3} \mathrm{Al}_{11}$ content varies from ten to one percent. For one sample, no evidence of the $\mathrm{Ce}_{3} \mathrm{Al}_{11}$ phase has been observed whereas that of $\mathrm{CeAl}_{2}$ has been clearly detected by the presence of only one weak specific heat anomaly at the ordering temperature of $\mathrm{CeAl}_{2}(3.8 \mathrm{~K})$. The intrinsic specific heat of $\mathrm{CeAl}_{3}$ is presently unknown. The high sensitivity of the samples not only to the parasitic phases but also to the defects [8] leads to a quite difficult problem. The experimental situation is similar to that known for other instable valency compounds such as TmSe [9]. Despite this difficulty, the difference between $\mathrm{CeAl}_{3}$ and the two well-ordered compound $\mathrm{CeAl}_{2}$ and $\mathrm{CeIn}_{3}$ is clearly shown by the temperature dependence of the entropy, since this representation masks the weak parasitic phase anomaly. For $\mathrm{CeAl}_{2}$ and $\mathrm{CeIn}_{3}$ a marked decrease of the entropy is observed at the temperature of the maxima of the specific heat whereas for $\mathrm{CeAl}_{3}$ the entropy follows a smooth temperature dependence.

2. Conclusion. - The two peaks generally observed in the specific heat of $\mathrm{CeAl}_{3}$ at 2.5 and $6 \mathrm{~K}$ seem due to the $\mathrm{Ce}_{3} \mathrm{Al}_{11}$ parasitic phase, they have been unambiguously related to the remanent properties.

Few experiments have been made on $\mathrm{Ce}_{3} \mathrm{Al}_{11}$ until now. A better understanding of its low temperature properties is crucial for the interpretation of the $\mathrm{CeAl}_{3}$ behaviour. $\mathrm{Ce}_{3} \mathrm{Al}_{11}$ is a striking case : the spectacular disappearance of one anomaly under pressure whereas the other anomaly is pressure independent is unex- 
plained. An interesting problem is the corresponding variation of the specific heat notably its low temperature behaviour. A future comparison with the two other magnetically well ordered compounds $\mathrm{CeIn}_{3}$ and $\mathrm{CeAl}_{2}$ will be fruitful for the understanding of these abnormal compounds.

\section{References}

[1] Barbara, B., Boucherle, J. X., Buevoz, J. L., Rossignol, M. F., Schweizer, J., Solid State Commun. 24 (1977) 481.

[2] Berton, A., Chaussy, J., Chouteau, G., Cornut, B., PeyRARD, J., TOURNIER, R., Valences instabilities, Rochester 1976, Edited by R. Parks (Plenum Press) 471 and ANDRES, K., Graebner, J. E., Hott, H., Phys. Rev. Lett. 35 (1975) L-1779.

[3] Mader, K. H., Swift, S. M., J. Phys. Chem. Solids 29 (1968) 1759.

[4] VAn DaAl, H. J., Buschow, K. H. J., Phys. Lett. 31 A (1970) 103.
[5] Andres, K., Grabner, J. E., Ott, H. R., Phys. Rev. Lett. 35 (1975) 1779.

[6] Berton, A., Chaussy, J., Chouteau, G., Cornut, B., PeyRARD, J., TOURNIER, R., Rare earths and actinides 1977. Proc. of the Int. Conf. on Rare earths and actinides. Durham 1977. Edited by W. D. Corner and B. K. Tanner. The Institute of Physics Bristol and London.

[7] Gomes de Mesquita, A. H. and Buschow, K. H. J., Acta Cryst. 22 (1967) 497.

[8] Edelstein, A. S., Majewski, R. E. and Blewitt, T. H., Valence instabilities (Rochester) 1976, p. 115.

[9] Tournier, R. and HoltzBERG, F., Valence instabilities (Rochester) 1976 , p. 303 